\title{
Fracture Toughness of Poly (Methyl Methacrylate)/Hydroxyapatite Denture Base Composite: Effect of Planetary Ball Milling Mixing
}

\section{Time}

\author{
Jamal Moammar Aldabib ${ }^{1 *}$ and Zainal Arifin Mohd Ishak ${ }^{2}$ \\ ${ }^{1}$ Faculty of Medical Technology, Bani Walid University, 1459 Bani Walid, Libya \\ ${ }^{2}$ School of Materials and Mineral Resources Engineering, Universiti Sains Malaysia, \\ 14300 Nibong Tebal, Pulau Pinang, Malaysia
}

*Corresponding author: jamalald71@gmail.com, jamalaldabib@bwu.edu.ly

Published online: 25 November 2021

To cite this article: Aldabib J. M. \& Mohd Ishak, Z. A. (2021). Fracture toughness of poly (methyl methacrylate)/hydroxyapatite denture base composite: Effect of planetary ball milling mixing time. J. Phys. Sci., 32(3), 103-116. https://doi.org/10.21315/jps2021.32.3.8

To link to this article: https://doi.org/10.21315/jps2021.32.3.8

\begin{abstract}
Hydroxyapatite (HA) has great potential as a reinforcing filler for poly (methyl methacrylate) (PMMA) denture base materials. Nevertheless, filler particles need to be homogeneously distributed throughout the PMMA particles to get the maximum benefit from using the filler. Therefore, the physical mixing of the powder components (PMMA and the filler) is strongly preferred to provide the required dispersion of the filler in the matrix. However, conventional techniques that have been tried, such as hand mixing and stirrer mixing techniques, were not effective. Therefore, the current study was designed to experimentally investigate the effect of different mixing times on the fracture toughness of PMMA/HA using a developed ball milling method. In this study, heat cured PMMA reinforced with $15 \mathrm{wt} \%$ HA ceramic powder was ground for different times (i.e., 10, 20, 30, and $40 \mathrm{~min}$ ) via the technique of planetary ball milling (PBM). The ground powder mixtures were used for the fabrication of denture base testing samples. The particle size and distribution of the PMMA/HA composites after milling for several times were determined by the laser light scattering technique. The X-ray diffraction (XRD) patterns of the PMMA/HA composites were obtained. However, no new phase was observed. The effects of mixing time using the PBM technique on the fracture toughness were investigated. The effect of mixing time on the microporosity (voids) on the fractured surface of PMMA/ HA was studied with field emission scanning electron microscopy (FESEM). Within the limitation of the current study, 30 min is considered the optimum mixing time for the tested PMMA/HA composite.
\end{abstract}

Keywords: poly (methyl methacrylate), hydroxyapatite, denture base materials, planetary ball milling, mixing time

(C) Penerbit Universiti Sains Malaysia, 2021. This work is licensed under the terms of the Creative Commons Attribution (CC BY) (http://creativecommons.org/licenses/by/4.0/). 


\section{INTRODUCTION}

Poly (methyl methacrylate) (PMMA) is commonly used for the fabrication of denture bases. ${ }^{1-3}$ Its inherited characteristics of easy handling and processing, low toxicity, and low cost together with reasonable physical and mechanical properties make PMMA a preferred material for dental applications. However, it behaves in a brittle manner when loaded, especially under an impact force. ${ }^{4}$ Research is currently ongoing to incorporate different materials to overcome the drawbacks and generally increase the strength of the acrylic material. Several ceramic powders are used as a reinforcement for PMMA, e.g., barium titanate, zirconium oxide, alumina, and hydroxyapatite (HA). ${ }^{4-7}$

Recently, a naturally calcium apatite $\left[\mathrm{Ca}_{5}\left(\mathrm{PO}_{4}\right)_{3} \mathrm{OH}\right]$ derived material called HA has been widely used by many workers as a reliable filler to attain a reinforced PMMA with improved mechanical, thermal, and rheological properties. The biodegradation, osteoconduction, osteointegration, and biocompatibility of the HA are the potential advantages behind its use as a reinforcement material for biomedical applications. Moreover, the stiffness, density, and bioactivity of HA make it a preferred reinforcement as a bone cement. ${ }^{8-12}$ Evidently, HA has been used as a filler in many polymer-based composites to modify the physical and mechanical performance in biomedical applications, such as high density polyethylene (HDPE) for bone substitutes. ${ }^{13-14}$

When processed and manufactured, the PMMA denture base material should have the sufficient mechanical requirements that are considered essential for optimum performance in the dental application. Although most applications in dentistry have a minimum mechanical property requirement, the prerequisite mechanical requirements for a successful PMMA/HA composite to be used in the oral environment are controlled by HA loading, particle size, and distribution. ${ }^{15-17}$

These mechanical requirements need to be tested before, during, and after mixing of the filler with the polymer to form a composite in the laboratory to assure the acceptance of the end-product as a denture base material. However, different variables during the milling process may affect the mechanical properties of the output mixture. Among these variables are the milling method, time, medium, temperature, rotation speed, and ball-to-powder ratio. The milling time is profoundly considered the most important controlling factor that influences the particular powder system and its workability in the composite. ${ }^{18}$ The milling time required is so chosen for each polymer-to-filler combination to achieve reduction in the particle size, ensuring a steady distribution of the filler particulates in the polymer matrix. These results in obtaining a homogeneous composite system that improves the mechanical properties. 
The unwanted effects of contamination and phase change are associated with a milling time that is longer than required. Therefore, it is desirable that the powder is milled just for the required duration and not any longer. This suggests the need to optimise the controlling factor of milling time if enhancing the biomechanical properties of the PMMA/HA composite is desired..$^{15}$ The objective behind the current study is to investigate the effect of the different mixing times on the fracture toughness of the PMMA/HA composite to assure that the best mechanical performance of the composite is obtained. In addition, savings in energy, time, and labour work will be attained along with a quality product for the proposed application in denture restoration.

\section{EXPERIMENTAL}

\subsection{Materials}

The materials adopted in this study were powder and liquid systems. The powder components consisted of PMMA (the average particle size as received was 88.4 $\mu \mathrm{m})$ with a high molecular weight [i.e., 996,000 gel permeation chromatography (GPC); Aldrich, Saint Louis, Missouri, USA], benzoyl peroxide (BPO) with particle size $\leq 106 \mu \mathrm{m}$ (Merck Chemical Company, Darmstadt, Germany), and HA ceramic powder with particle size (as received) $5 \pm 1 \mu \mathrm{m}$ (Fluidinova, Maia, Porto, Portugal). The liquid components consisted of methyl methacrylate (MMA) (Aldrich, Saint Louis, Missouri, USA) stabilised with $0.0025 \%$ hydroquinone and ethylene glycol dimethacrylate (EGDMA) (Aldrich, Saint Louis, Missouri, USA) as a cross linking agent.

\subsection{Sample Preparation}

In the laboratory, a planetary ball milling (PBM) machine (Firtsch Pulverisette 5, $\mathrm{GmbH}$, Duisburg, Germany) with the aid of a zirconium oxide jar and balls was used to mix the solid component (powder) for 10, 20,30, and 40 min to study the effect of mixing time on the performance of the PMMA/HA composite. The powder to ball weight ratio (PBR) was 1:10, and the running speed of mixing was 150 RPM. The mixing was stopped every 3 min and continued after 6 min during the run time to prevent the problems of overheating and premature polymerisation. The powder and liquid $(\mathrm{P} / \mathrm{L})$ were mixed according to the standard dental laboratory usage. After reaching the dough stage, the mixture was packed into a mould and pressed under $14 \mathrm{MPa}$ of pressure using a compression moulding machine (MESTRA R-030350, Talleres Mestraitua, S.L., Bizkaia, Spain) at room temperature for $30 \mathrm{~min}$. The final polymerisation (curing process) was carried out using a water bath 
at $78^{\circ} \mathrm{C}$ for $1.5 \mathrm{~h}$. The mould was then left to cool slowly at room temperature. The samples were next removed. The procedures adopted in this study were consistent with those of the prescribed standard method for preparing conventional denture base in the dental laboratory. ${ }^{19}$

\subsection{Characterisation}

\subsubsection{Particle size and distribution analysis}

The particle size distribution of PMMA/HA composites after milling several times was determined by the laser light scattering technique (Sympatec GmbH particle size analysis, Clausthal-Zellerfeld, Germany). The particle size of the composition was analysed by the HELOS particle size analysis Windox 5 software (ClausthalZellerfeld, Germany).

\subsubsection{Density and porosity measurements}

The density of the samples was determined according to the ASTM D 792 waterdisplacement method (method A). The specific gravity was calculated using the following equation: ${ }^{20}$

$$
\text { Specific gravity }=\frac{a}{[(a+w)-b]}
$$

$\mathrm{a}=$ mass of specimen in air

$\mathrm{b}=$ mass of specimen and sinker in water

$\mathrm{w}=$ mass of totally immersed sinker and partially immersed wire.

The porosity content of the samples was also calculated according to the ASTM $\mathrm{C} 20$ - 00 using the following equation: ${ }^{21}$

$$
\text { Apparent porosity }(\mathrm{P}) \%=\frac{\mathrm{W}-\mathrm{D}}{\mathrm{W}-\mathrm{S}} \times 100
$$

where $\mathrm{D}$ is the dry weight of the specimen, $\mathrm{S}$ is the suspended weight, and $\mathrm{W}$ is the saturated weight.

\subsubsection{X-ray diffraction (XRD)}

XRD patterns of the mixed powder mixtures (PMMA/HA) were characterised using a Bruker Advanced X-ray Solution diffractometer (Billerica, Massachusetts, USA) with $\mathrm{Cu} \mathrm{K} \alpha$ and a step scan mode of $0.051^{\circ} / 358 \mathrm{~s}$ to make sure that there 
was no disordering of the HA crystal structure, which could occur as a function of exposure to intensive mixing with the PBM. The $2 \theta$ was taken from $2^{\circ}$ to $40^{\circ}$.

\subsubsection{Field emission scanning electron microscopy (FESEM)}

The fractography and morphology features of the PMMA/HA composites were examined by FESEM (Zeiss SUPRA 35VP LEO, Oberkochen, Germany). The samples were mounted on an aluminium stud with double-sided carbon tape and sputter-coated with aurum/palladium alloys (Heidolph REAX2- Schwabach, Germany) in a Bio-Rad Polaron sputter coater (Polaron Equipment Ltd, London, UK) to enhance the image resolution and avoid electrostatic charging and to obtain an image resolution.

\subsubsection{Fracture toughness}

The fracture toughness was determined using the single edge notch bending test (SEN-B) according to ISO 13586:2000. The specimens were tested in a moulded plate. Thickness, $\mathrm{B}=4 \mathrm{~mm}$, width, $\mathrm{W}=20 \mathrm{~mm}$, span length, $\mathrm{L}=64 \mathrm{~mm}$, overall length $=80 \mathrm{~mm}$, and notch length, $\mathrm{a}=4 \mathrm{~mm}$. A natural crack was generated by tapping the specimens on a new razor blade placed in the notch. The SEN-B specimens were tested at a cross-head speed of $1.00 \mathrm{~mm} / \mathrm{min}$. At least five samples were tested for each formulation. The critical stress intensity factor $\left(\mathrm{K}_{\mathrm{IC}}\right)$ values for fracture toughness were calculated using the following equation:

$$
\begin{aligned}
& \mathrm{K}_{\mathrm{IC}}=\frac{3 P S a^{1 / 2} Y}{2 t w^{2}} \\
& \mathrm{Y}=1.93-3.07(\mathrm{a} / \mathrm{w})+14.53(\mathrm{a} / \mathrm{w})^{2}-25.11(\mathrm{a} / \mathrm{w})^{3}+25.8(\mathrm{a} / \mathrm{w})^{4}
\end{aligned}
$$

where

$\mathrm{Y}=$ geometrical correction factor

$\mathrm{S}=$ span length $(\mathrm{mm})$

$\mathrm{a}=$ notch length $(\mathrm{mm})$

$\mathrm{P}=$ load at peak $(\mathrm{N})$

$\mathrm{t}=$ specimen thickness $(\mathrm{mm})$

$\mathrm{w}=$ specimen width $(\mathrm{mm})$. 


\subsubsection{Statistical analysis}

The data were statistically analysed using one-way analysis of variance (ANOVA) followed by Scheffe's post-hoc method to identify the significant differences between the groups. Descriptive statistics were carried out using a statistical software program [Statistical Package for the Social Sciences (SPSS) version 23, IBM, New York, USA]. Data were analysed at a significance level of 0.05 .

\section{RESULTS AND DISCUSSION}

\subsection{Particle Size Analysis for the Powder Mixtures}

Table 1 shows the particle size of the PMMA/HA powder mixtures that were subjected to the PBM technique for several milling times (i.e., 10, 20, 30, and $40 \mathrm{~min}$ ). It was observed that the PMMA/HA powder mixtures milled for $10 \mathrm{~min}$ had the smallest particle size $(24.78 \mu \mathrm{m})$ and the largest surface area $\left(0.54 \mathrm{~m}^{2} / \mathrm{g}\right)$. However, the particle size slightly increased to $27.01 \mu \mathrm{m}$ when the milling time was increased to $20 \mathrm{~min}$. It is interesting to note that the particle size decreased to $25.41 \mu \mathrm{m}$ after going to $30 \mathrm{~min}$ and increased again to $30.13 \mu \mathrm{m}$ when the milling time was $40 \mathrm{~min}$. A similar observation was reported by Tham et al. ${ }^{15}$ This can be attributed to the fact that during the milling, the powder particles are repeatedly flattened, cold welded, fractured, and re-welded. Whenever two balls collide, some quantity of powder is trapped in between the balls. The force of the collision plastically deforms the powder particles, leading to hardening and fracture. The new created surfaces make it possible for the particles to weld together, leading to an increase in particle size. In the early stages of milling, the particles are somewhat soft; therefore, they have a high tendency to weld together and form large particles. A large range of particle sizes developed, even bigger than the starting particles in some cases. With continued deformation, the particles get work hardened and fracture, resulting in a reduced particle size..$^{18,22}$

Table 1: Particle size of the PMMA/HA composite upon being subjected to PBM.

\begin{tabular}{lll}
\hline Mixing time $(\mathrm{min})$ & Particle size, $\mathrm{X}_{50}(\mu \mathrm{m})$ & Specific surface area $\left(\mathrm{m}^{2} / \mathrm{g}\right)$ \\
\hline $10 \mathrm{~min}$ & 24.78 & 0.5435 \\
$20 \mathrm{~min}$ & 27.01 & 0.4202 \\
$30 \mathrm{~min}$ & 25.41 & 0.4986 \\
$40 \mathrm{~min}$ & 30.13 & 0.2331 \\
\hline
\end{tabular}

Note: $\mathrm{X}_{50}=$ median value of particle size distribution 


\subsection{Density and Porosity Measurement}

Table 2 shows the effect of mixing time on the density and porosity content of the PMMA/HA composites. The density of the PMMA/HA composites increased as the mixing time increased and reached a maximum value of $1.25 \mathrm{~g} / \mathrm{cm}^{3}$ for 30 min of mixing time, after which the density decreased to $1.22 \mathrm{~g} / \mathrm{cm}^{3}$ as the mixing time increased to $40 \mathrm{~min}$. The increased density of the PMMA/HA composites is mostly caused by the decrease in the porosity content. Table 2 shows a reduction in the void content to $47.48 \%$ and $80.05 \%$ for the composites mixed for $20 \mathrm{~min}$ and $30 \mathrm{~min}$, respectively. On the other hand, the introduction of a non-uniform distribution and agglomeration of HA particles as a function of long-term mixing led to the formation of voids and porosities that eventually altered the density across the sample..$^{23}$ The density is often a single parameter that is related to the physical and mechanical properties of polymers. For example, the softening temperature, chemical resistance, stiffness, tear strength, hardness, and Young's modulus tend to increase with increasing density. ${ }^{24,25}$ Therefore, every factor that affects the density and the structure of polymers and polymer composites would affect their mechanical properties as well.

Table 2: Effect of mixing time on the density of the PMMA matrix filled with $15 \mathrm{wt} \%$ HA.

\begin{tabular}{lrcc}
\hline $\begin{array}{l}\text { Mixing time } \\
(\mathrm{min})\end{array}$ & $\begin{array}{l}\text { Density } \\
\left(\mathrm{g} / \mathrm{cm}^{3}\right)\end{array}$ & $\begin{array}{l}\text { Porosity content } \\
(\%)\end{array}$ & $\begin{array}{l}\text { Reduction in the porosity } \\
\text { content }(\%)\end{array}$ \\
\hline 10 & 0.72 & 16.64 & 0 \\
20 & 0.88 & 8.74 & 47.48 \\
30 & 1.25 & 3.32 & 80.05 \\
40 & 1.22 & 4.21 & 74.69 \\
\hline
\end{tabular}

\subsection{XRD Analysis}

Figure 1 illustrates the XRD patterns of the PMMA/HA powder mixture samples after different mixing times (i.e., 10, 20, 30, and $40 \mathrm{~min}$ ) using the PBM technique. The peaks in the XRD spectrum recorded at $2 \theta=25^{\circ}-26^{\circ}, 28^{\circ}-31^{\circ}, 32^{\circ}-35^{\circ}$, and $40^{\circ}$ for all the samples indicate the presence of HA. A similar observation was reported by Balamurugan et al. ${ }^{26}$ However, it can be clearly seen that the diffraction peaks of the ground powder mixtures after different mixing times exhibited the same intensity and a broader peak base. This indicates that there is no obvious change in the XRD spectra of the PMMA/HA powder mixtures after being subjected to PBM. This proves that the milling from 10-40 min did not change the amorphous nature and structure of the PMMA/HA composite. This observation was in agreement with the one made by Tham et al. ${ }^{15}$ The increase 
in the temperature could accelerate the transformation process and results in the decomposition of supersaturated solid solutions or new metastable phases formed during milling. ${ }^{22}$

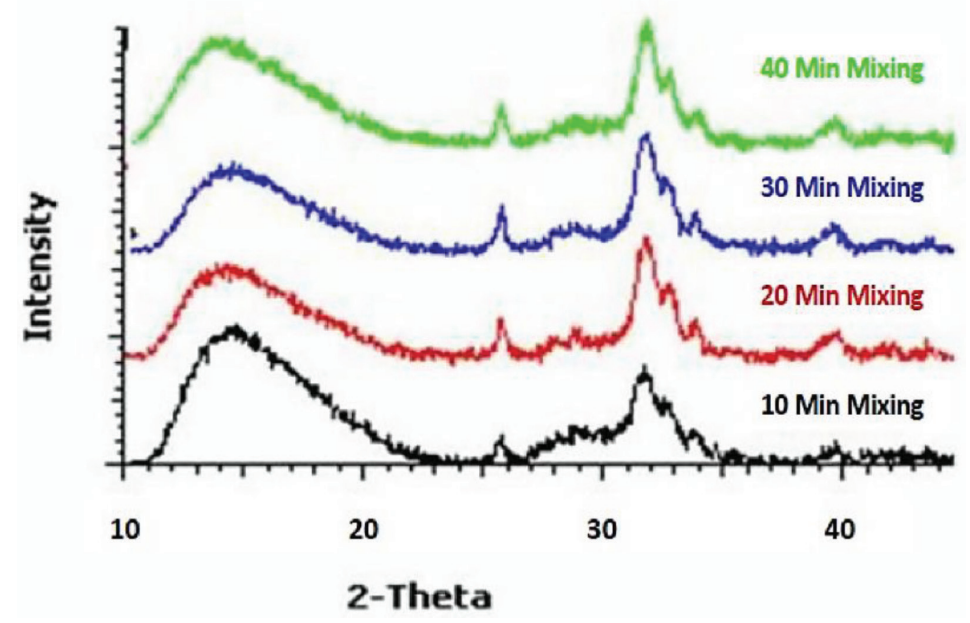

Figure 1: XRD patterns of PMMA/HA $15 \mathrm{wt} \%$ with different mixing times.

\subsection{Fracture Toughness Test}

The tendency of a composite material containing a crack to resist fracture is described by the fracture toughness. Therefore, a material with a low fracture toughness value indicates it is undergoing brittle fracture, while a material with a high fracture toughness value indicates it is undergoing ductile fracture. ${ }^{27}$ Figure 2 illustrates the output results of the fracture toughness testing of the PMMA composite samples as a function of mixing time. The observations show that the fracture toughness responses of the samples reach the maxima at $1.29 \mathrm{MPa} \cdot \mathrm{m}^{1 / 2}$ when the mixing runs for $30 \mathrm{~min}$, after which a decrease was recorded. The upward increase in the fracture toughness values with the increase in the milling time up to $30 \mathrm{~min}$ is due to the improvement in the filler-matrix distribution. ${ }^{28}$ 


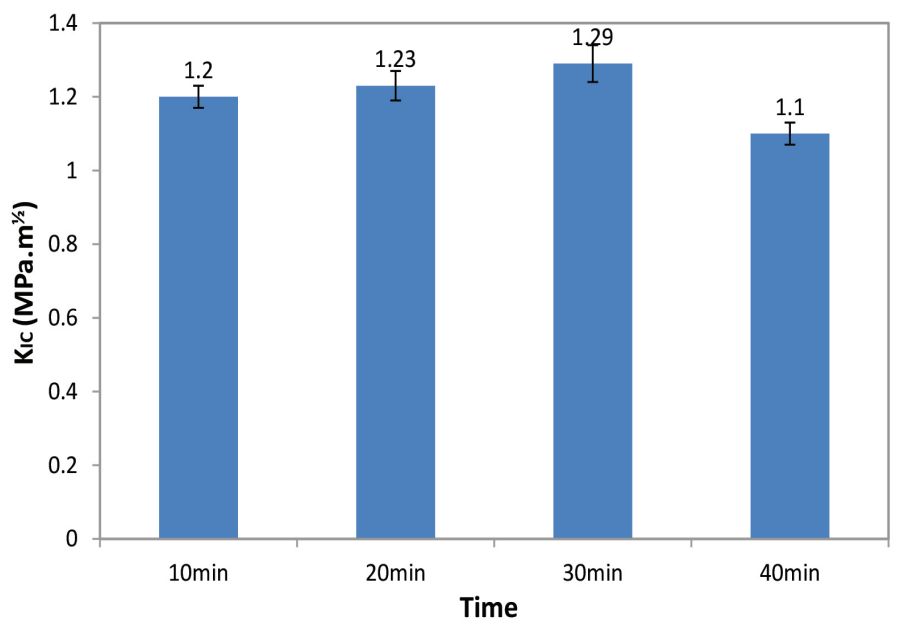

Figure 2: The effect of mixing time on the fracture toughness of the PMMA matrix filled with $15 \mathrm{wt} \%$ HA.

Table 3 summarises the statistical analysis of the $\mathrm{K}_{\mathrm{IC}}$ values of the PMMA/HA composite as a function of different mixing times. Based on the statistical analysis, all mean differences in the $\mathrm{K}_{\mathrm{IC}}$ values that were observed between the tested groups were significant $(p<0.05)$. The particle size and distribution have a significant influence on the fracture toughness of the acrylic denture base composite. As the particle size decreases, the fracture toughness improves due to the larger specific surface area (more surface contact area between the matrix and filler). ${ }^{29}$ With the good distribution, more surface contact area and interlocking between the PMMA matrix and filler can resist fracture by improving the stress transferring and distribution between the strong and brittle HA filler particles and the flexible acrylic resin matrix. ${ }^{30}$

Table 3: Statistical summary for the $\mathrm{K}_{\mathrm{IC}}$ values (MPa.m ${ }^{1 / 2}$ ) of PMMA/HA $15 \mathrm{wt} \%$ composite as a function of different mixing times.

\begin{tabular}{lcccllc}
\hline \multicolumn{7}{c}{ Descriptive statistics } \\
\hline Group & N & Minimum & Maximum & Mean & SD & $p$-value \\
\hline $\mathbf{1 0}$ min & 5 & 1.20 & 1.21 & 1.2020 & 0.00447 & 0.001 \\
$\mathbf{2 0}$ min & 5 & 1.22 & 1.24 & 1.2300 & 0.00707 & 0.001 \\
$\mathbf{3 0}$ min & 5 & 1.28 & 1.30 & 1.2940 & 0.00548 & 0.001 \\
$\mathbf{4 0}$ min & 5 & 1.09 & 1.12 & 1.1000 & 0.01225 & 0.001 \\
\hline
\end{tabular}

Note: All mean differences are statistically significant at the 0.05 level $(p<0.05)$. 
The decrease in the $\mathrm{K}_{\mathrm{IC}}$ value as a function of the long term mixing is due to the agglomeration of filler particles in the matrix. ${ }^{31}$ It is believed that the agglomeration of the filler particles plays a major role in the formation of voids and macropores in the matrix, which has a weakening effect in such cases. ${ }^{32}$ According to Arencón and Velasco, ${ }^{33}$ if the filler-matrix bonding is poor, the filler will detach easily from the matrix to create voids. Voids grow in the stress direction with additional plastic deformation, creating dimple-like holes around the particles. As a function of applying additional load, the rest of the matrix will deform under shear stress, causing the previous voids to coalesce together and leading to the final fracture.

\subsection{FESEM}

Figure 3 illustrates the FESEM micrographs that were taken at low magnification for the fractured surface of randomly selected samples from the PMMA/HA composites prepared from the ground powder mixtures for various times (i.e., $10,20,30$, and $40 \mathrm{~min})$. It can be clearly seen that the mixing time has a strong effect on the presence of the micro porosity (voids). From Figure 3, the number of voids on the fractured surface of the PMMA/HA composite ground for $10 \mathrm{~min}$ is approximately 100 . The existence of micro voids on the fractured surface indicates that the cavities can be associated with the debonding of the filler agglomerates from the PMMA matrix during the fracture process. It is believed that de-bonding is the initiation of the debonding mechanism especially in polymer composites. Because of the low polarity and, consequently, low surface free energy, de-bonding is considered an important mechanism in polymer composites. Additionally, interfacial adhesion is usually weak, and separation of the matrix-filler interface takes place.

In Figure 3, a 47.48\% reduction of the void number (approximately 55 voids) was recorded on the fractured surface of the composite ground for $20 \mathrm{~min}$. This reduction was $80.05 \%$ (approximately 10 voids) for the composite ground for $30 \mathrm{~min}$. This significant reduction in the void number can be attributed to the heat generated after grinding, which reduces the moisture content in the sample. ${ }^{15}$ Compared to the composite ground for $30 \mathrm{~min}$, a significant increase was recorded in the void number to $74.69 \%$ (approximately 35 voids) on the fractured surface of the composite ground for $40 \mathrm{~min}$. This can be attributed to the agglomeration of filler particles as a function of long-term milling. According to Mohamed, ${ }^{32}$ as a result of the large particle size, stress concentrations will be increased, which contribute to the formation of large cavities and voids. As discussed earlier, agglomeration might also take place during the curing process (polymerisation), causing poor mechanical properties. 


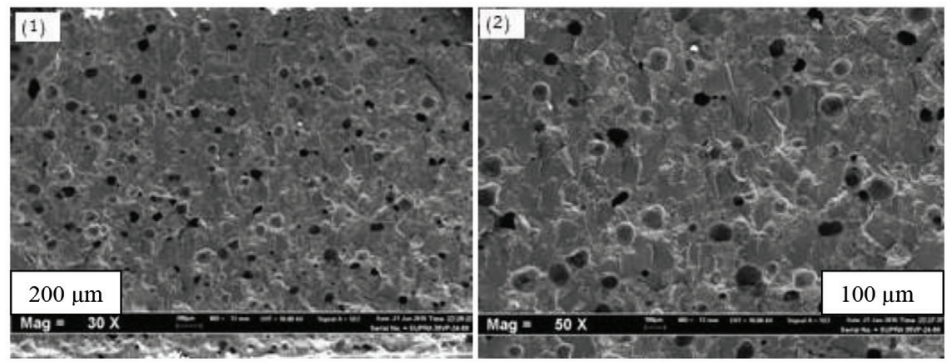

(a)

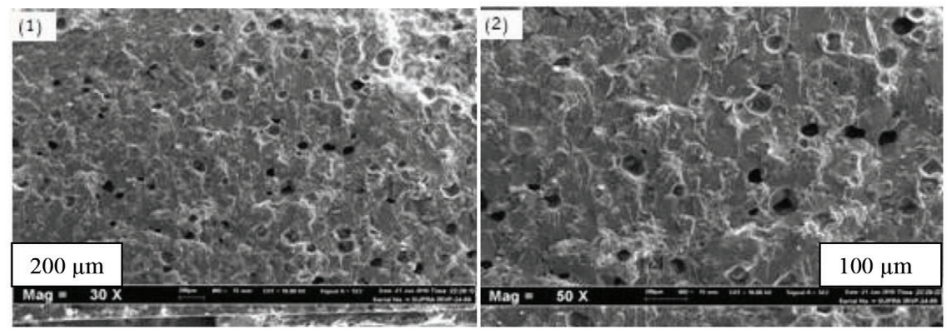

(b)

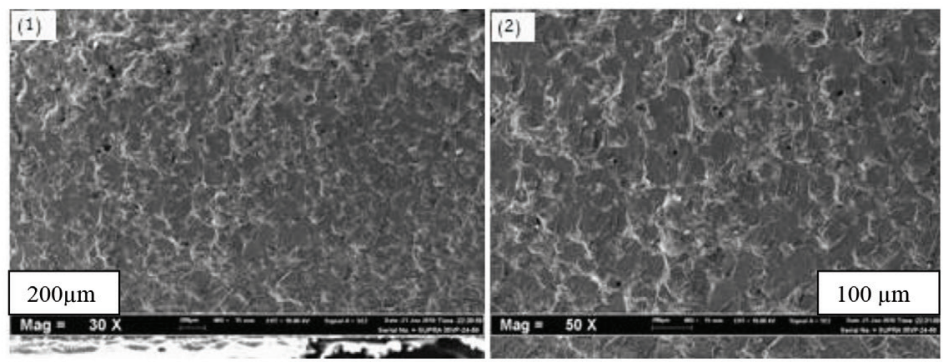

(c)
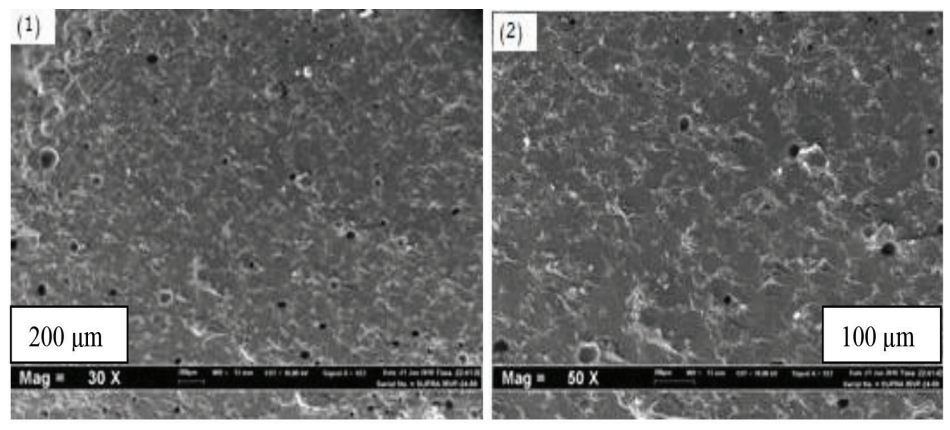

(d)

Figure 3: FESEM micrographs expose the fractured surface of flexural samples, (a) 10 min mixing, (b) 20 min mixing, (c) 30 min mixing, and (d) 40 min mixing at different magnifications: (1) $30 \times$ and (2) $50 \times$. 


\section{CONCLUSION}

It was determined that the particle size of the PMMA/HA composite was affected by using the PBM technique as a function of time. The particle size of the PMMA/ HA powder mixtures was significantly influenced by the mixing time using the PBM technique. It is believed that the agglomeration of PMMA/HA powder mixtures occurred after 30 min of mixing. Based on the XRD patterns, the intensive mixing of the PMMA/HA powder mixtures could lead to disordering of the crystal structure of HA. It has been proved that the milling from 10-40 min did not change the amorphous nature and structure of the PMMA/HA composite. The fracture toughness was significantly affected by the particle size and distribution. Based on the mechanical testing, a mixing time of $30 \mathrm{~min}$ is considered the optimum mixing time for maintaining the highest mechanical properties in the selected composite, after which the samples may lose their flexural quality and likely break as mixing proceeds. As a function of mixing time, the presence of the micro porosity (voids) on the fractured surface of PMMA/HA can be controlled.

\section{ACKNOWLEDGEMENTS}

The authors would like to thank Universiti Sains Malaysia and the Ministry of Higher Education and Scientific Research of Libya for the financial support (grant no. 1375/700).

\section{REFERENCES}

1. Kurt, M. \& Bal, B. T. (2019). Effects of accelerated artificial aging on the translucency and color stability of monolithic ceramics with different surface treatments. J. Prosthet. Dent., 121(4), 712.e1-712.e8. https://doi.org/10.1016/j. prosdent.2019.01.014

2. Salernitano, E. \& Migliaresi, C. (2003). Composite materials for biomedical applications: A review. J. Appl. Biomater. Biomech., 1(1), 3-18.

3. Sivakumar, R. (1999). On the relevance and requirements of biomaterials. Bull. Mater. Sci., 22(3), 647-655. https://doi.org/10.1007/BF02749981

4. Aldabib, J. (2020). Reinforcement of poly (methyl methacrylate) denture base material. Dent. Med. J. Rev., 2(2), 46-53.

5. Raj, et al. (2018). Fracture resistant, antibiofilm adherent, self-assembled PMMA/ $\mathrm{ZnO}$ nano formulations for biomedical applications: Physico-chemical and biological perspectives of nano reinforcement. Nanotechnology, 29(30), 305704. https://doi.org/10.1088/1361-6528/aac296 
6. Aldabib, J. M. \& Ishak, Z. A. M. (2020). Effect of hydroxyapatite filler concentration on mechanical properties of poly (methyl methacrylate) denture base. SN Appl. Sci., 2(4), 732. https://doi.org/10.1007/s42452-020-2546-1

7. Heness, G. \& Ben-Nissan, B. (2004). Innovative bioceramics. Mater. Forum, 27, 104-114.

8. Sheng, T. J. et al. (2018). Review on poly-methyl methacrylate as denture base materials. Malays. J. Microsc., 14(1): 1-16.

9. Hing, K. A. (2005). Bioceramic bone graft substitutes: Influence of porosity and chemistry. Int. J. Appl. Ceram. Technol., 2(3), 184-199. https://doi.org/10.1111/ j.1744-7402.2005.02020.x

10. Legeros, R. Z. (1988). Calcium phosphate materials in restorative dentistry: A review. Adv. Dent. Res., 2(1), 164-180. https://doi.org/10.1177/0895937488002 0011101

11. Hariharan, K. \& Arumaikkannu, G. (2018). Electron beam deposition of hydroxyapatite coating on polyamide substrate for biomedical application. In Thomas, S. et al. (Eds.). Functionalized engineering materials and their applications, 1st ed. Florida, USA: Apple Academic Press, 243-254.

12. Wang, M. (2003). Developing bioactive composite materials for tissue replacement. Biomaterials, 24(13), 2133-2151. https://doi.org/10.1016/S01429612(03)00037-1

13. Ali Sabri, B. et al. (2021). A review on enhancements of PMMA denture base material with different nano-fillers. Cogent Eng., 8(1), 1875968. https://doi.org/10 $.1080 / 23311916.2021 .1875968$

14. Zuo, Y. et al. (2007). Novel bio-composite of hydroxyapatite reinforced polyamide and polyethylene: Composition and properties. Mater. Sci. Eng. A, 452-453, 512517. https://doi.org/10.1016/j.msea.2006.11.138

15. Tham, W. L., Chow, W. S. \& Mohd Ishak, Z. A. (2010). Flexural and morphological properties of poly (methyl methacrylate)/hydroxyapatite composites: Effects of planetary ball mill grinding time. J. Reinf. Plast. Compos., 29(13), 2065-2075. https://doi.org/10.1177/0731684409344899

16. Suryanarayana, C. (2001). Mechanical alloying and milling. Prog. Mater. Sci., 46(1-2), 1-184. https://doi.org/10.1016/S0079-6425(99)00010-9

17. Zafar, M. S. (2020). Prosthodontic applications of polymethyl methacrylate (PMMA): An update. Polymers, 12(10), 2299. https://doi.org/10.3390/ polym 12102299

18. Muhammad Firdaus, S. et al. (2021). Properties improvement of acrylic resin for denture application: Effect of single and hybrid types of fillers with different weight loadings. Plast. Rubber Compos., 50(7), 329-339. https://doi.org/10.1080/ 14658011.2021.1897261

19. McCabe, J. F. \& Walls, A. W. G. (2013). Applied dental materials. Hoboken, New Jersey: Wiley-Blackwell.

20. Elshereksi, N. W. et al. (2014). Thermal characterisation of poly (methyl methacrylate) filled with barium titanate as denture base material. J. Phys. Sci., 25(2), 15-27. 
21. Hamdi, D. A. (2020). Investigating the mechanical and microstructure properties of ceramic-PMMA polymer composite. AIP Conference Proceedings, 2213(1), 020043-1-020043-8. https://doi.org/10.1063/5.0000429

22. El-Eskandarany, M. S. (2001). Mechanical alloying: For fabrication of advanced engineering materials, 1st ed. Norwich, New York: William Andrew Publishing, 62-93. https://doi.org/10.1016/B978-081551462-6.50007-X

23. Molino, G. et al. (2020). Biomimetic and mesoporous nano-hydroxyapatite for bone tissue application: A short review. Biomed. Mater., 15(2), 022001. https://doi.org/10.1088/1748-605X/ab5f1a

24. Younesi, M. \& Bahrololoom, M. E. (2009). Effect of temperature and pressure of hot pressing on the mechanical properties of PP-HA bio-composites. Mater. Des., 30(9), 3482-3488. https://doi.org/10.1016/j.matdes.2009.03.011

25. Mysiukiewicz, et al. (2020). Mechanical, thermal and rheological properties of polyethylene-based composites filled with micrometric aluminium powder. Mater., 13(5), 1242. https://doi.org/10.3390/ma13051242

26. Balamurugan, A. et al. (2004). Development and spectral characterization of poly (methyl methacrylate)/hydroxyapatite composite for biomedical applications. Trends Biomater. Artif. Organs, 18(1), 41-45.

27. Anderson, T. L. (2017). Fracture mechanics: Fundamentals and applications. Boca Raton: CRC Press. https://doi.org/10.1201/9781315370293

28. Schulze, K. A., Zaman, A. A. \& Söderholm, K.-J. M. (2003). Effect of filler fraction on strength, viscosity and porosity of experimental compomer materials. $J$. Dent., 31(6), 373-382. https://doi.org/10.1016/S0300-5712(03)00091-5

29. Alhareb, A. O., Akil, H. M. \& Ahmad, Z. A. (2017). Impact strength, fracture toughness and hardness improvement of PMMA denture base through addition of nitrile rubber/ceramic fillers. Saudi J. Dent. Res., 8(1-2), 26-34. https://doi. org/10.1016/j.sjdr.2016.04.004

30. Aldabib, J. M. (2021). Effect of silane coupling agent content on mechanical properties of hydroxyapatite/poly (methyl methacrylate) denture base composite. J. Sci. Perspect., 5(1), 37-45. https://doi.org/10.26900/jsp.5.1.04

31. Naito, M. et al. (2018). Nanoparticle technology handbook. Amsterdam: Elsevier.

32. Mohamed, S. H. (2006). Mechanical, physical and biological properties of denture base poly (methyl methacrylate) filled ceramic fillers. $\mathrm{PhD}$ thesis, Universiti Sains Malaysia, Malaysia.

33. Arencón, D. \& Velasco, J. I. (2009). Fracture toughness of polypropylenebased particulate composites. Mater., 2(4), 2046-2094. https://doi.org/10.3390/ ma2042046 